\section{Sex, love and science}

\author{
Serious treatments of science in fiction can be \\ illuminating for both scientists and non-scientists.
}

\section{Susan Gaines}

A nineteenth-century woman naturalist burns with thwarted scientific curiosity, revelling in a clandestine experiment. Three physicists working to reconcile quantum mechanics and relativity form a tragic triangle of erotic, filial and intellectual love. Another solves the problem he most wanted to solve, but the answer, the fame and his solicitous lover all fail to satisfy his longings. Astronomy expands and nurtures the inner life of a man so ugly that he worships beauty as if it were a transcendent god.

These tales of sex, love and science come from fiction - a story from Andrea Barrett's Ship Fever, Lisa Grunwald's novel The Theory of Everything, Rebecca Goldstein's Properties of Light and Chet Raymo's Dork of Cork. In recent years, novelists have been mining science for metaphors, faddishly sprinkling literature with scientific allusions, but these books go beyond allusion to focus directly on the scientific enterprise. Not science fiction, with its emphasis on futuristic technologies, or Jurassic Parkstyle commercial entertainment, these are literary explorations of scientific culture, featuring characters whose lives are informed by direct involvement with scientific knowledge.

Forty years after C. P. Snow sounded an alarm about the cultural divide between science and the humanities, with Alan Sokal only recently taking post-modern philosophers to task for their abuse of physics, a few novelists - some of them also scientists or former scientists - have been approaching science with their literary inquiries. Whether Snow's two cultures have fused, or fragmented, or been obliterated by commercialism and technology, the rift between scientists and non-scientists remains - not for the inevitable gap in their knowledge, but for the way they perceive knowledge -

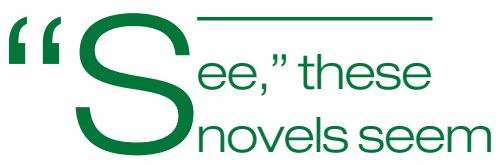

to tell us, "science is common knowledge; science is the stuff of life and literature." and novels such as these may play a small but interesting role in closing it. They give a daringly intimate, idiosyncratic, irreverent, passionate and honest view of science and its personal and philosophical dilemmas, a perspective that is rarely seen in public discourse.

In Anna McGrail's Mrs Einstein, the illegitimate daughter of a famous physicist to acknowledge her and twists her mathematical talent into a vehicle for revenge. In Louis B. Jones's Particles and Luck, a physicist bumbles through a suburban comedy of errors, and yearns for "the ordinary manly pleasure of certainty" and "a job to do" rather than a life spent in "scrupulous wimpy professional self-doubt". With the First World War brewing, two naturalists struggle to resolve the paradox of human altruism and natural selection in Michel Rio's novella Dreaming Jungles. Richard Powers' The Gold Bug Variations spins a metaphorical web of love, music and 1950s molecular biology, while affirming the infectious power of scientific curiosity. Rick relationship between a petroleum geologist, the land he's exploring, and the ageing oil magnate who mentors him.

The language and culture of science, which are designed to nullify the personal themes easily. A vocabulary of unequivocal and avoidance of the first-person singular well. But when it comes to intersections between science and values, both public and personal, the unbridled poetry and literary as a mountain breeze wafting through a hermetically sealed building. Recently, after a presentation of my novel about a geochemist, a carbon-cycle researcher in the audience said to me, "It's hard to express this stuff", and added, "Actually, most of the scientists I know are knee-jerk environmentalists". He was talking about their personal reactions to their data as a thing apart from the data or their production, referring to the scene I'd read. It was treacherous, oftavoided territory for scientists, but as a novelist I'd marched right in, and he seemed grateful for the excuse to explore it.

And what of the data in these novels? What about the science itself? Can we have meaningful discussions of scientific knowledge in fiction? Simon Mawer meets this becomes obsessed with her father's refusal Bass's Where the Sea Never Ends tells of the and subjective, do not accommodate such definitions, proclivity for the passive tense, serves the objective treatment of science sensibility of a novelist can be as welcome

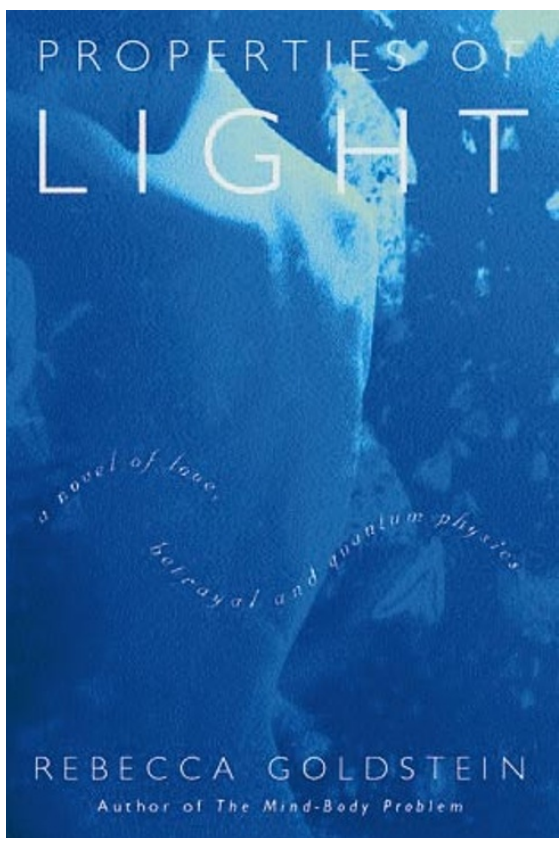

Matter of the heart: love, intellectual envy and fundamental questions of physics are combined in Rebecca Goldstein's Properties of Light.

challenge head-on in Mendel's Dwarf, the story of a geneticist whose scientific outlook is forged by the overriding fact of his life his physical deformity - and whose view of the world is so dominated by his knowledge of genetics that his thoughts come replete with journal references. Mawer's novel does what many popular science books and textbooks fail to do in their rush to serve up the facts - it dips beneath the smooth, unrippled surface of established knowledge to the wandering lines of thought and experiment that support it, the rationale for the facts.

Chemist Carl Djerassi has coined the term 'science-in-fiction' for his own novels, and states clearly that his goal is to educate. The literary novel is, by its nature, nondidactic; not a lesson in science, nor one in morality, it can only be an elucidation of either, or of both. Ironically, it is precisely this quality that can serve Djerassi's purpose, in ways that other forms of discourse do not. The novels discussed here are not attempts to disseminate scientific knowledge, to popularize science or to sensitize scientists. They belong to no genre or school, vary wildly in style and theme, and make their own rules about the depth and rigour with which they discuss science. But implicit in this small body of literature is the assumption - the presumption — that science is approachable. "See," these novels seem to tell us, "science is common knowledge; science is the stuff of life and literature." And perhaps, by presuming so, they nudge us closer to making it true.

Susan Gaines crossed over from science to fiction more than a decade ago. She is the author of the novel Carbon Dreams (Creative Arts Book Co.). 